\title{
Implementation and certification of LPV approach and options for VFR aerodromes
}

\author{
Jakub Kraus \\ Department of Air Transport, \\ Department of Air Transport, Faculty of Transportation \\ Sciences, Czech Technical University \\ Horská 3, Praha 2, 128 03, Czech Republic \\ e-mail: krausjak@fd.cvut.cz
}

\author{
Jakub Ninger \\ Department of Air Transport, \\ Department of Air Transport, Faculty of Transportation \\ Sciences, Czech Technical University \\ Horská 3, Praha 2, 128 03, Czech Republic \\ e-mail: ningejak@fd.cvut.cz
}

\author{
Karel Jeřábek \\ Department of Air Transport, \\ Department of Air Transport, Faculty of Transportation Sciences, Czech Technical University
}

Horská 3, Praha 2, 128 03, Czech Republic

\begin{abstract}
This article focuses on general LPV approach certification for aerodromes. It also indicates the problematic parts of the current certification process and shows the direction for possible certification of instrument approaches at uncontrolled aerodromes.
\end{abstract}

Keywords - instrument approach, LPV, IFR, aerodrome, VFR

\section{INTRODUCTION}

The introduction of RNP approaches is a complex process consisting of many stages, which require the cooperation of all participating organizations. This process should be in accordance with the recommendations and standards of ICAO, which issued Doc 9849 - GNSS Manual for that purpose. Another key document for the implementation and certification of all types of approaches is ICAO Doc 8168 - PANS-OPS Vol. II.

\section{PLANNING}

The first and one of the most important stages of the implementation is the selection of aerodromes at which will be the GNSS approach published. The planning should be approached from the perspective of the entire region. In Europe, this is stated in document called Navigation Strategy for ECAC issued by EUROCONTROL and in the conditions of the Czech Republic, planning and introduction of new approaches is currently managed by the Concept of development of navigation in the Czech Republic until 2020. This concept suggests the implementation of RNP approaches (mainly LNAV/VNAV (APV Baro) and LPV minima (APV SBAS)) - they must be implemented on all IFR runways in 2016.

General rules where it is advantageous to introduce the APV approach are:

- Aerodromes near areas with dense population - a continuous descent approach reduces noise pollution
- Aerodromes with meteorological conditions don't requiring frequent operation in LVP

- Aerodrome, where there may be interference with signal of ground navigation equipment

- Aerodrome, where it is not possible to install a ground navigation equipment (e.g. due to unfavourable terrain)

- Aerodromes without precision approach

- Aerodromes handling regularly aircrafts heavier than $5700 \mathrm{~kg}$

It is recommended to establish implementation team, which includes representatives of all participating organizations - the aerodrome operator, CAA, air traffic management experts, air traffic control agents, security experts, specialists in the creation of approaches and, ultimately, pilots and environmental movement representatives. The team collects the following information about the aerodrome:

- Runways equipment

- Meteorological data (statistic information about wind, visibility, cloud base, ...) - this data can be used to determine the most suitable approach solution

- GNSS Infrastructure - all APV approaches are subject to sufficient availability of EGNOS

- Other infrastructure - meteorological instruments (options for measuring RVR, wind, pressure, ... - for aerodromes with already published instrument approach should be this equipment already available), existing terrestrial radionavigation devices can also be used, for example, for construction of the missed approach procedure

The implementation team should also assess the condition of traffic in the airspace around the aerodrome and to assess the impact of the introduction of RNP approach. Another important element in the introduction is communication with aircraft operators at aerodromes and to assess whether is their airborne equipment adequate for the proposed type of approach. 


\section{A. Requirements for aerodrome equipment}

ICAO Annex 14 or any other international standards still doesn't specify aerodrome facilities specifically for RNP approach. In all international standards and within Europe it is considered to introduce RNP approach only on instrument runways for the time being. The general requirements are:

- Sufficient length and width of the runways

- Obstacles in the approach area

- The availability of meteorological information

- Adequate lighting equipment and signs

- Appropriate system of taxiways

LPV approach is based on the evaluation of aircraft position from global positioning systems advanced with SBAS, which doesn't requires any ground radio navigation aids.

PROCESS 1

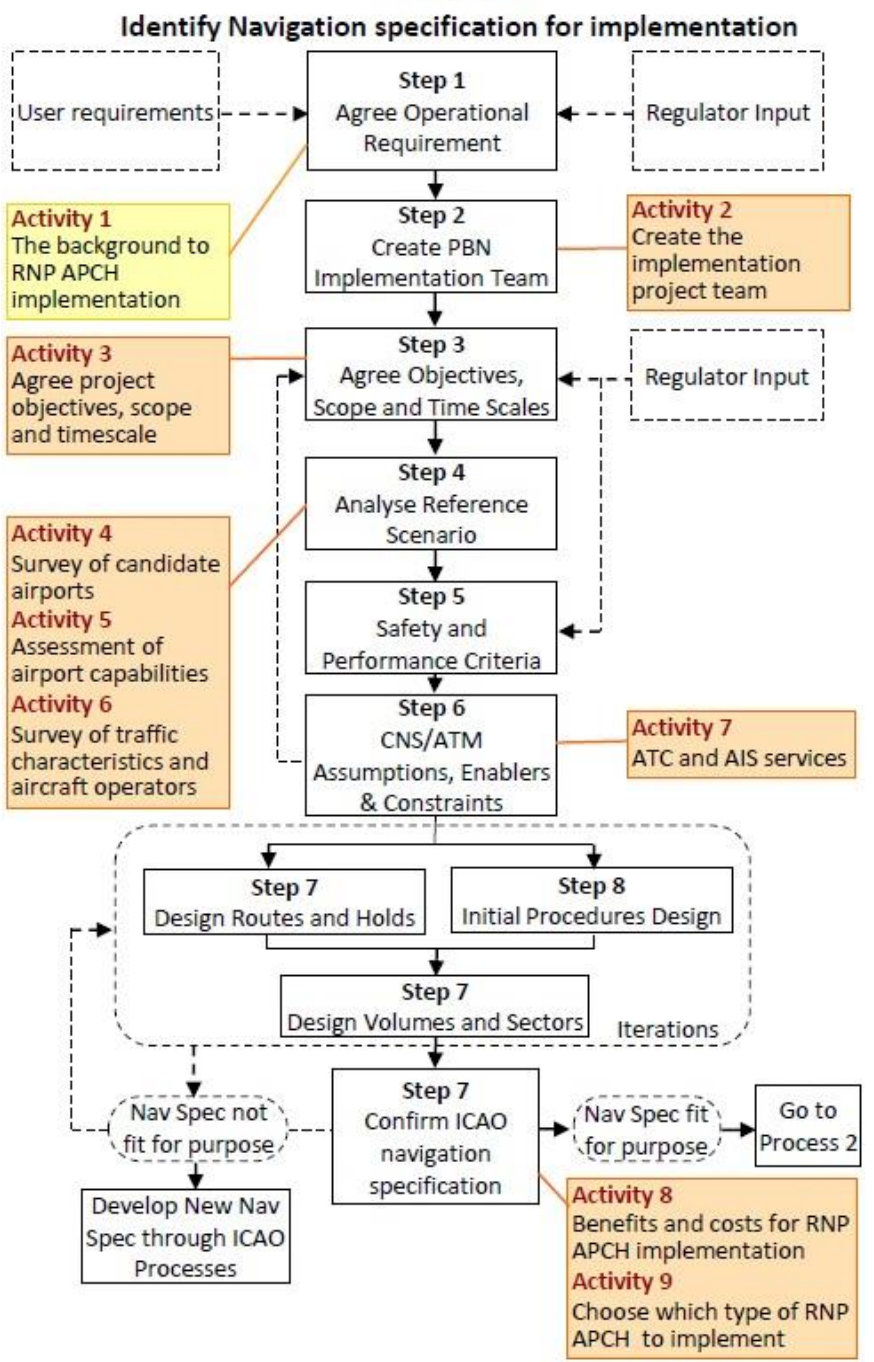

Figure 1. Planning and construction of approach procedures[14]

\section{B. Effect on LPV landing minima by aerodromes surrounding}

LPV approach Decision Height is influenced by many factors. These include (6):
- Obstacle Free Zones

- Glidepath Qualification Surface (GQS)

- Runway Lighting and Markings

- Taxiway Considerations

- Airport Surveys

- Runway Protection Zone

\section{VALIDATION - CERTIFICATION}

Validation is the final step in implementing the new procedures. Its aim is to verify quality and safety parameters of approach - including obstacles, terrain in the approach area and navigation data and includes also an assessment, if the approach could be flown in practice. Validation must be conducted by an independent organization. The procedure is set out in the following documents:

- ICAO PANS-OPS Doc 8168

- ICAO Doc 8071

- ICAO Doc 9906 Vol. 5 - Validation of instrument flight procedures

Validation itself has two parts - ground and flight.

\section{A. Ground validation}

Ground validation is mandatory for all new approaches. Its aim is to collect all data (namely the obstacle limitation surfaces and the related height clearances) and to check their required accuracy.

Part of the validation is to create a package that includes:

- Map of all obstacles in the approach area

- Complete documentation describing the obstacles and terrain, including obstacle planes

- Detailed description of the procedure segment by segment

- Map and vertical profile of the procedure

- Data of all points and holding patterns in the procedure

- Confirmation that the coverage of navigation equipment is sufficient

- The design approach map for flight validation aircraft crew

If there is during ground validation founded that some data needs to be verified in flight, then flight validation must follow. The reason for the execution of the flight validation may be a failure to comply with international standards, the speed limit in one segment, inadequate segment lengths, steep descent gradient, or a lot of obstacles in the surrounding area.

\section{B. Flight validation}

Flight validation may be required to verify the adequate functioning of all navigation systems, on which is the procedure based. It must be made by qualified inspector with sufficiently equipped aircraft. Specific procedures of flight validation are defined in ICAO Doc 8071 or in related national regulations and directives. The aim is to prove fly-ability, exploring, for example, crew workload in its various stages, readability and clarity of procedure documentation (maps ...), verifying the 
accuracy of new navigational database (points, distance ...) and also verifying the obstacles.

Finally, in the flight validation of the procedure, the inspector shall state of one of the following classifications:

- Procedure without restrictions

- Procedure with restrictions - does not meet the requirements of the regulations entirely, it is not dangerous for air traffic

- The procedure is inapplicable - does not meet all regulatory requirements, it may be dangerous

\section{Certification of LPV approach}

Certification of LPV approach should follow the recommendations and standards of ICAO, in this case, the Doc 8071 - Manual on Testing of Radio Navigation Aids Vol. II Testing of Satellite-based radio navigation systems. This document is not freely available and by the latest information chapter 3 describing SBAS systems is not yet finalized.

After its completion and approval of this document it will, beyond description of systems and individual types of approach (Chapter 1), accurately describe the requirements necessary for certification of LPV approach:

- Ground validation - requirements for aerodrome surveillance equipment, testing interferences of GNSS systems, ...

- Flight validation - pre-flight testing, test flight procedures, forms and standards for writing final reports, a description of the test equipment of the airplane ...

Flight validation for LPV approach certification is required at all times (including modifications of established approach) and for each and every type of approach separately (if it is introduced more types simultaneously).

In Europe, several projects such as project ACCEPTA (Accelerating EGNOS Adoption in Aviation) or GIANT (GNSS Introduction in the Aviation Sector) deals with implementation and certification of RNAV (primarily avionics and equipment on board aircraft).

Since there have not yet been established international standards on APV, the certification of these approaches runs under existing standards for precision and non-precision approaches and according to national regulations and directives. Certification of these approach do not require any testing of ground radio navigation equipment (when it is not use for missed approach), but compared to the classical approach it is necessary to focus on monitoring and documentation of GNSS and SBAS availability and signal quality.

\section{Certification Authorities}

Within the European Union, for certification and the providing of air navigation services, is responsible each Member State. In the case of the Czech Republic, the authority responsible for the administration of civil aviation under section $5 \S 3$ of regulation No. 49/1997 (Civil Aviation Law) is Civil Aviation Authority Czech Republic. Under CAA falls the competence to determine the aerodromes suitability. The certification procedure must be in accordance with all applicable regulations and documents and is also controlled by internal directives.

\section{PROCESS 2}

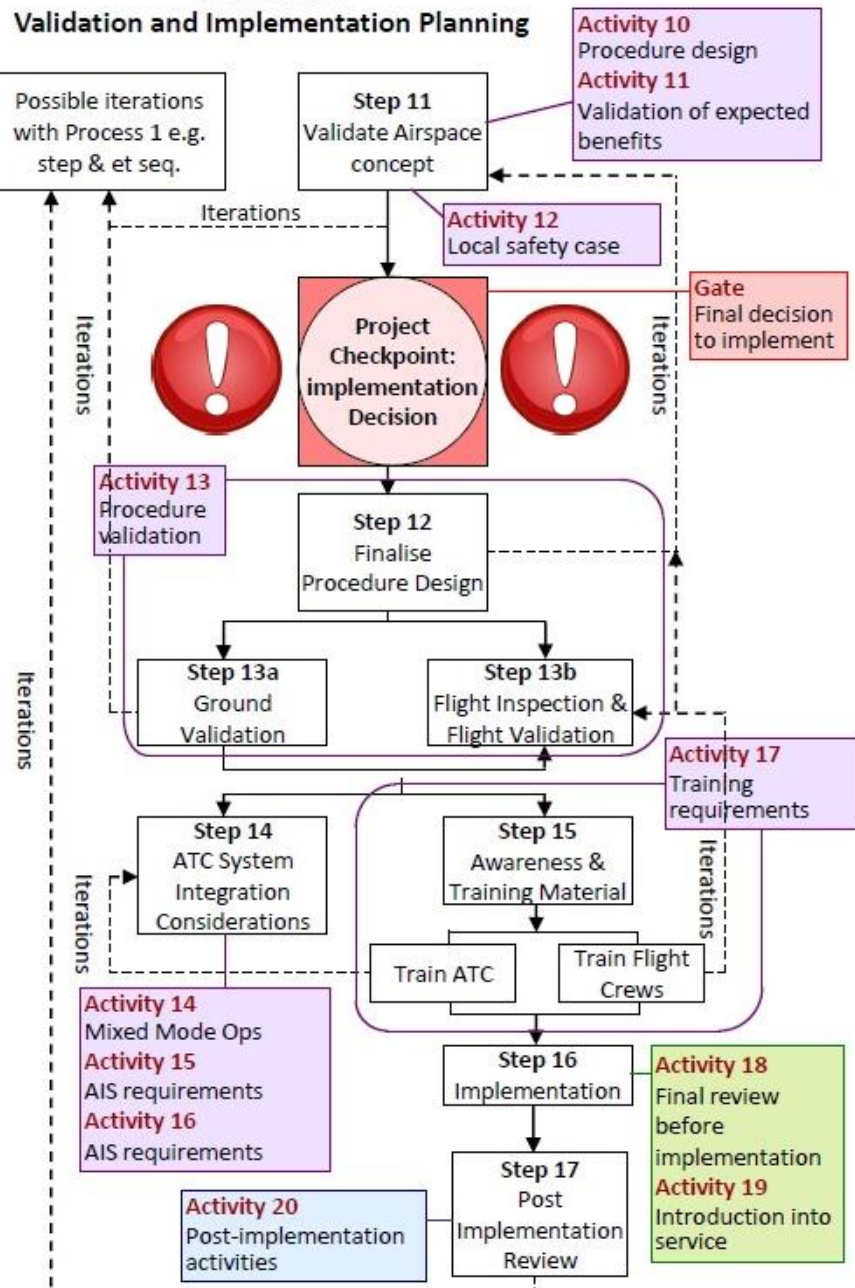

Figure 2. Validation and implementation of the procedure [14]

\section{CERTIFICATION AT UNCONTROLLED AERODROMES}

Uncontrolled aerodromes have currently a unique opportunity for development, since, as mentioned above, all regulations for LPV approach certification are still not created. However, efforts on the introduction and subsequent certification of LPV approaches at uncontrolled aerodromes are prevented by several obstacles, which could be fortunately easily removed. The problem is to ensure compatibility with already applicable regulations.

The best choice is an introduction of LPV approaches across an entire region. Because of this there will be possible to adjust base rules for a larger number of VFR aerodromes, thereby eliminating a large number of obstacles, among which may be included the technical equipment of the aerodromes and uncontrolled airspace. In fact, it could mean the creation of an instrument approach to the aerodrome, which has only a grass runway, centerline lights, no air traffic control service and is located in uncontrolled airspace. 


\section{CONCLUSION}

This article describes the process of implementation and certification of LPV approach how it should look according to currently available rules. Such a process is very complicated, because it's basically a pre-operational safety improvement that cannot be underestimated. Unfortunately, incomplete safety regulations do not help, but on the other hand allow a new perspective on the situation in process of their creation. This could be essential for the development in general aviation.

It would be also useful to consider and determine whether it is possible to reduce the requirements for the introduction of instrument approach at aerodromes, or in extreme case, to create a subgroup, respectively even a new group of rules of the air. This could start rapid development in air transport and, ultimately, increased accessibility and availability of the Czech Republic by air.

\section{ACKNOWLEDGEMENTS}

This paper was supported by the Grant Agency of the Czech Technical University in Prague, grant No. SGS12/165/OHK2/2T/16.

\section{REFERENCES}

[1] AIP ČR [online]. Available at $<$ http://lis.rlp.cz/ais_data/www_main_control/frm_cz_aip.ht $\mathrm{m}>$

[2] Navigation strategy for ECAC. [online]. Eurocontrol, 1999. Available at:

$<$ http://www.ecacnav.com/downloads/Navigation\%20Strate gy.pdf $>$

[3] GNSS v Evropě. Czech Space Portal. [online] Ministerstvo dopravy ČR, 2011. [Cit. 10. 12 2012.] Available at:

<http://www.czechspaceportal.cz/3-sekce/gnsssystemy/gnss-v-evrope/>

[4] ICAO Doc 9849 Global Navigation Satellite System Manual. [PDF] Montreal : ICAO, 2005. Available at: $<$ http://www.icao.int/Meetings/PBNSymposium/Documents/9849_cons_en[1].pdf >

[5] L 8168 Letecký předpis. [online]. Available at: <http://lis.rlp.cz/predpisy/predpisy/index.htm>

[6] Holzer, Mark. GPS LPV Approach Establishment. [online]. FAA, 2010. Available at:

<http://www.faa.gov/airports/great_lakes/about_airports/bis _ado/bis_ado_web/media/handouts/GPS2010MJH.pdf>

[7] Duka, Tomáš. Implementace PBN v ČR. [online] Praha : ŘLP a.s., s.p., 2011. Available at: $<$ lis.rlp.cz/cz/prezentaceGA/Nav_PBN.pps>

[8] Koncepce rozvoje navigačního prostředí v podmínkách ČR. [PDF] Jeneč : К̌LP a.s. s.p., 2012.

[9] Policy for the Application of Performance-based Navigation in UK/Irish Airspace. [online] London, Dublin : UK Civil Aviation Authority, Irish Aviation Authority, 2011. Available at:

<http://www.caa.co.uk/docs/33/Policy\%20for\%20the\%20A pplication $\% 20$ of $\% 20$ Performance-

based $\% 20$ Navigation $\% 20$ in\%20UK_Irish\%20Airspace\%20 -\%20Signed\%20111013.pdf>
[10]. CAR PART VIII - Instrument flight procedure design requirements. [online] Abu Dhabi : GCAA UAE, 2011. Available at:

<http://www.gcaa.gov.ae/en/ePublication/admin/Library\%2 0Pdf/Civil\%20Aviation\%20Regulations\%20(CARs)/AIR\% 20NAVIGATION\%20REGULATIONS/SUBPART\%206 $\% 20-$

$\% 20 \%$ 20INSTRUMENT\%20FLIGHT\%20PROCEDURE \%20DESIGN\%20REQUIERMENT.pdf>

[11] Guidance Material for the Flight Inspection of RNAV Procedures. [PDF]. Eurocontrol, 2005. Available at: <http://www.ecacnav.com/downloads/Flight\%20Inspection $\% 20$ of $\% 20$ RNAV $\% 20$ Procedures $\% 20$ Released $\% 20$ Issue $\%$ 20Edition\%203.pdf>

[12] Meeting about ICAO Doc 8071 - Manual on Testing Radio Navigation Aids. Spohnheimer, Nelson. [online] Montreal : FAA, 2004. Available at:

<http://www.navcanada.ca/ContentDefinitionFiles/IFIS/po werpoint/Workshops/ICAO_Doc_8071_Spohnheimer.pdf>

[13] ICAO Doc 8071 - Manual on testing of radio navigation aids - testing of ground-based radio navigation systems. [PDF] Montreal : ICAO, 2000. Available at: <http://portal.aerocivil.gov.co/portal/pls/portal/!PORTAL. wwpob_page.show?_docname=7975314.PDF $>$

[14] Guidance Material for The Implementation of RNP APCH Operations. [online]. EUROCONTROL, 2012. Available at: <http://www.paris.icao.int/documents_open_meetings/show _file.php?id=1530> 